\title{
62-jährige Patientin mit juckendem Hauttumor
}

Der englische Titel des Beitrags „62-jährige Patientin mit juckendem Hauttumor“ (Dtsch Med Wochenschr 2016; 141: 105) lautet: „62-year old woman with itching skin tumor”. 